\title{
Relationships between Five-Factor Personality Model and Anxiety: The Effect of Conscientiousness on Anxiety
}

\author{
Jiayin Fan \\ Department of Psychology, University of California, Berkeley, USA \\ Email: jf318@berkeley.edu
}

How to cite this paper: Fan, J. Y. (2020). Relationships between Five-Factor Personality Model and Anxiety: The Effect of Conscientiousness on Anxiety. Open Journal of Social Sciences, 8, 462-469.

https://doi.org/10.4236/jss.2020.88039

Received: May 18, 2020

Accepted: August 28, 2020

Published: August 31, 2020

\begin{abstract}
The purpose of this study is to examine the relation between anxiety and the Big Five personality traits, especially conscientiousness and extraversion. Methods: 121 participants aged $13-55(\mathrm{M}=31.94)$ were evaluated anxiety levels using the BIS scale of anxiety; for conscientiousness and extraversion, they were measured by Big-Five Factor Markers. Results: There was a significant negative correlation between anxiety and conscientiousness; The results also showed that 1) While considering the multivariate model, conscientiousness and extraversion did not have independent effects on anxiety; a mediation effect existed. 2) There existed an interaction effect between conscientiousness and extraversion: for people who were high on extraversion, conscientiousness was less strongly related to anxiety. Conclusion: Results suggested that a small amount of variance in anxiety can be explained by conscientiousness and extraversion.
\end{abstract}

\section{Keywords}

Personality, Big-Five, Anxiety, Conscientiousness, Extraversion

\section{Introduction}

Craske MG et al. (2009) defined anxiety as "Anxiety is a future-oriented mood state associated with preparation for possible, upcoming negative events." Anxiety is one of the most common psychological problems among people of all age, which adversely affects both mental and physical health of people. In modern society, a large amount of people is experiencing different levels of anxiety. There are many factors that can influence people's anxiety level, such as environment, work and tasks and relationship with others etc. Besides external reasons, internal traits can also lead to people's difference in anxiety level. One of 
the most important traits is personality. One reliable model to evaluate personality is Five Factor Model (FFM), consisted of five major traits extraversion, conscientiousness, openness, neuroticism, and agreeableness. Conscientiousness, which is the personality trait of being careful and principled, is possibly related to anxiety level (Kotov et al., 2010).

Past research revealed that conscientiousness had the main effect on anxiety. The research of Harris \& Dollinger (2003) examined whether differences in personality traits could have an association with anxiety about aging. In this study, researchers let students answer two scales, which were for personality traits and anxiety about aging. The result was that anxiety about aging is negatively related to conscientiousness. However, researchers also pointed out limitations in their study. The proportion of explained variation was not good enough because additional psychological variables, such as well-being and identity, were not considered in the study. Vernon, Evans, \& Frissen's (2016) research on dimensions of personality and Library Anxiety also included a model evaluating the relationship between conscientiousness and extraversion. Their participants were students from multiple disciplines. The scale of Library Anxiety and the Big Five Inventory were sent to participants. Their result was that "agreeableness and Conscientiousness together explained more than $35 \%$ of the variability" (Vernon, Evans, \& Frissen, 2016). Limitations of the study were the small sample size $(\mathrm{N}=40)$ and the outdated instrument (original LAS). Research also showed that the relationship between conscientiousness and anxiety could be explained by a potential confounding variable, extraversion, which is another personality in FFM. There was not study directly evaluating the multivariate model including conscientiousness and extraversion as independent variables. However, research indicated that extraversion was also related to anxiety. The research of Middeldorp et al. (2006) was a longitudinal study, in which participants were twins and their family members (parents and siblings). In this study, questionnaires were sent to those participants every two years, beginning in 1991 and ending in 1997. The questionnaires included question assessing neuroticism, extraversion, sensation seeking, and dependent variables depression, anxious depression, somatic anxiety, and anxiety. The result suggested that there was a negative relationship between extraversion and anxiety. The research of Vreeke \& Muris (2012) examining the relationship between Big Five personality traits and anxiety among children also found extraversion's effect on anxiety. They conducted the study by giving forms and questionnaires about anxiety or behavior inhibition to parents and then gathered the results to analyze. The result was that there was a negative association between extraversion and anxiety.

There was also a past research revealing the interaction effect between conscientiousness and extraversion. The research of Naragon-Gainey \& Simms (2017) examined the three-way interaction effect of neuroticism, extraversion, and conscientiousness in a psychiatric sample. Researchers used "two omnibus personality inventories and a diagnostic interview" (Naragon Gainey \& Simms, 2017) to evaluate participants' scores on personality traits and disorders. The 
result showed three-way interaction effect of neuroticism, extraversion, and conscientiousness on disorders such as social anxiety, PTSD, and GAD. There existed several limitations: first is that they "cannot draw any conclusions regarding causal directions of the observed associations." (Naragon-Gainey \& Simms, 2017); In addition, the variation explained by the three-way interaction was small.

Although there has been researching examining the relationship between conscientiousness and anxiety, rare studies focused on the model only including extraversion as a confounding factor and the model evaluating an interaction effect between conscientiousness and extraversion. Most past research examined clinical disorders such as social anxiety and depression but not general anxiety. In this case, the study was designed to test the effect of conscientiousness on anxiety.

\section{Hypothesis}

\subsection{Hypothesis 1}

The first hypothesis is that conscientiousness will have a main effect on anxiety level. The null hypothesis is that conscientiousness has no effect on anxiety (H10). The alternative hypothesis is participants reporting high on conscientiousness will be low on anxiety (H1a).

\subsection{Hypothesis 2}

The effect of conscientiousness on anxiety will depend on participants' extraversion. The null hypothesis is extraversion will not influence the relationship between conscientiousness and anxiety (H20). The alternative hypothesis is that the relationship between conscientiousness will be weakened while extraversion is included in the model $(\mathrm{H} 2 \mathrm{a})$.

\subsection{Hypothesis 3}

The hypothesis is that there will be an interaction effect based on extraversion. The null hypothesis is conscientiousness's effect on anxiety will not depend on extraversion (H30). The alternative hypothesis is conscientiousness' effect on anxiety depends on extraversion (H3a).

\section{Methods}

\subsection{Participants}

There were 127 responses, and seven responses were removed: five of them were blank, and the rest two responses had incorrect inputs in gender and age. Of those 121 participants in the study, ranging from 13 to 55 years old and with an average age of $31.9,36 \%$ of participants $(\mathrm{N}=44)$ indicated gender as male, $64 \%$ participants $(\mathrm{N}=77)$ indicated gender as female and no participant indicated gender as other. There were no criteria and all respondents were eligible. No incentive was given to participants. To recruit participants, online survey links created by Qualtrics were sent through email and multiple social media both in 
the U.S. and China, including Facebook, QQ, and Wechat.

\subsection{Procedures}

In this study, participants first clicked on the link to the online survey which was shared by email or social media. Participants would fill out the anonymous survey consisted of total 15 questions: The first two were demographic questions about age and gender. The type of question asking participants' age was text entry. The question about gender was a multiple choice including three items-female, male and other. Next, they answered questions measuring anxiety, conscientiousness, and extraversion. There were five questions about anxiety and four questions for each conscientiousness and extraversion, with no scrambled sequence. Finally, participants submitted the answered survey, and their answers were recorded automatically.

\subsection{Measures}

Anxiety: Anxiety was measured using the BIS scale of anxiety (Carver \& White, 1994) with a self-report design. Five questions were chosen from the BIS scale of anxiety: three were negatively scored and two were positively scored. In each question, the response scale was from $1-4$, while $1=$ very true for me, $2=$ somewhat true for me, 3 = somewhat false for me, and $4=$ very false for me. For example, one question was "Get stressed out easily". In response to that question, participants who chose 1 had the highest level of anxiety.

Conscientiousness and extraversion: Conscientiousness and extraversion were measured through Big-Five Factor Markers (Goldberg, 1992) with a self-report design. I chose four questions for each independent variable. Every independent variable had three negatively scored questions and one positively scored questions. In each question, the response scale was from 1 (Strongly Agree) to 5 (Strongly Disagree). For example, one negatively scored question was "Am always prepared." In response to that question, participants who chose 1 had the highest conscientiousness.

\subsection{Descriptive Statistics}

Table 1 details the mean, standard deviations, range and alpha reliability for three continuous variables in the study (Figure 1). Overall, participants' anxiety levels were slightly high $(\mathrm{M}=2.30, \mathrm{SD}=.62$, alpha $=.70)$. Participants' were generally high on conscientiousness $(\mathrm{M}=3.70, \mathrm{SD}=.67$, alpha $=.65)$. Extraversion scores had a mean value of $2.93(\mathrm{SD}=.69$, alpha $=.54)$.

Table 1. Descriptive statistics of anxiety, conscientiousness and extraversion.

\begin{tabular}{ccccc}
\hline Variable & M & SD & Range & Alpha \\
\hline Anxiety & 2.30 & .62 & 2.60 & .70 \\
Conscientiousness & 3.70 & .67 & 3.00 & .65 \\
Extraversion & 2.93 & .69 & 3.67 & .54 \\
\hline
\end{tabular}

All three variables are continuous. Higher score indicates greater of trait measured $(\mathrm{N}=121)$. 

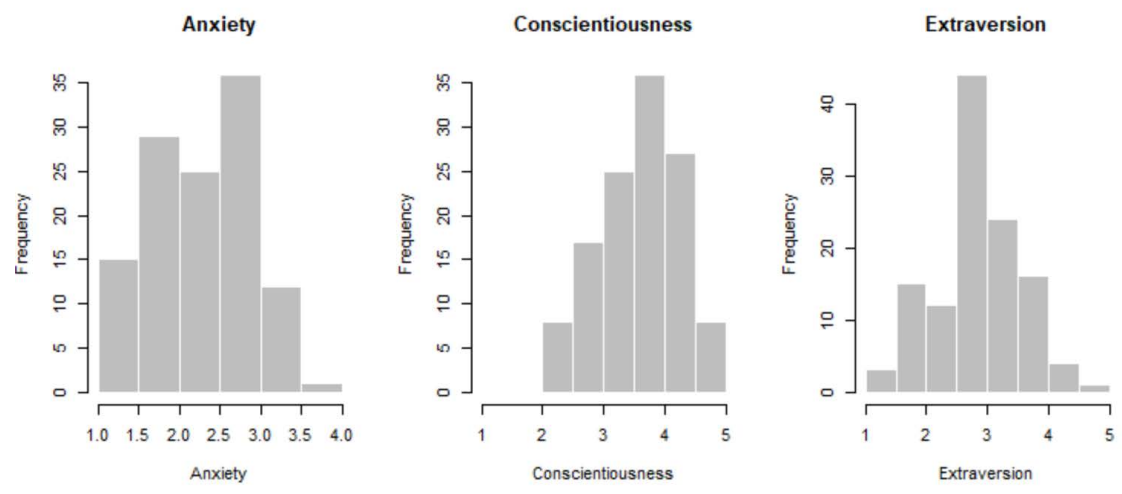

Figure 1. Descriptive data of key variables.

\section{Results}

To test my first hypothesis, a series of linear regressions were run to predict anxiety from conscientiousness, extraversion, and their interaction effect. Because the scale of anxiety was different from the scale of conscientiousness and extraversion, each variable was standardized. Results of those tests are presented in Table 2 .

\subsection{Hypothesis 1}

To test hypothesis 1, two bivariate linear regression models were run: the first one was the relationship between conscientiousness and anxiety, and another one was the relationship between extraversion and anxiety (Figure 2). As the first model showed, conscientiousness had a negative effect on anxiety $(\beta=-.31$, $95 \% \mathrm{CI}=[-.47, .15], \mathrm{t}(120)=3.56, p<.01)$, participants who were high on conscientiousness were low on anxiety. There was a negative relationship between extraversion and anxiety $(\beta=-.22,95 \% \mathrm{CI}=[-.38,-.05], \mathrm{t}(120)=2.40, p<.05)$, participants who were high on extraversion were generally low on anxiety.

\subsection{Hypothesis 2}

To test hypothesis 2 , a multivariate regression was tested to see whether the relationship between conscientiousness and anxiety could be explained by extraversion. The result of multivariate model suggested that although the relationship between conscientiousness and anxiety is weakened while extraversion was including in the model, indicating that there was a mediation effect, the negative effect still existed and was significant $(\beta=-.27,95 \% \mathrm{CI}=[-.44, .11], \mathrm{t}(120)=$ $1.71, p<.01)$.

\subsection{Hypothesis 3}

For hypothesis 3, a model was tested with interaction effect between conscientiousness and extraversion (Figure 3). The result suggested that there existed an interaction effect between conscientiousness and extraversion, conscientiousness was less strongly related to anxiety for people who were high on extraversion. However, the interaction effect was not significant $(\beta=.20,95 \% \mathrm{CI}=[-.15, .59]$, 
$\mathrm{t}(120)=1.13, p>.05)$.

Table 2. Bivariate multivariate correlations and interaction effect between anxiety, conscientiousness and extraversion.

\begin{tabular}{|c|c|c|c|c|}
\hline \multicolumn{5}{|c|}{ Standardized $\beta \mathrm{s}$} \\
\hline Estimated Effects & Model 1 & Model 2 & Model 3 & Model 4 \\
\hline Conscientiousness & $\begin{array}{c}-.31^{\star * *} \\
{[-.47, .15]}\end{array}$ & - & $\begin{array}{c}-.27^{\star *} \\
{[-.44,-.11]}\end{array}$ & $\begin{array}{c}-.26^{\star *} \\
{[-.43,-.09]}\end{array}$ \\
\hline Extraversion & - & $\begin{array}{c}-.22^{\star} \\
{[-.38,-.05]}\end{array}$ & $\begin{array}{c}-.15 \\
{[-.33, .02]}\end{array}$ & $\begin{array}{c}-.14 \\
{[-.32, .02]}\end{array}$ \\
\hline Conscientiousness $\times$ Extraversion & - & - & - & $\begin{array}{c}.20 \\
{[-.15, .59]}\end{array}$ \\
\hline \multicolumn{5}{|l|}{ Model Summary } \\
\hline $\mathrm{R}^{2}$ & .09 & .05 & .12 & .13 \\
\hline F-Test & $\begin{array}{c}12.62 \\
(1,116)\end{array}$ & $\begin{array}{c}5.74 \\
(1,114)\end{array}$ & $\begin{array}{c}7.76 \\
(2,113)\end{array}$ & $\begin{array}{c}5.61 \\
(3,112)\end{array}$ \\
\hline
\end{tabular}
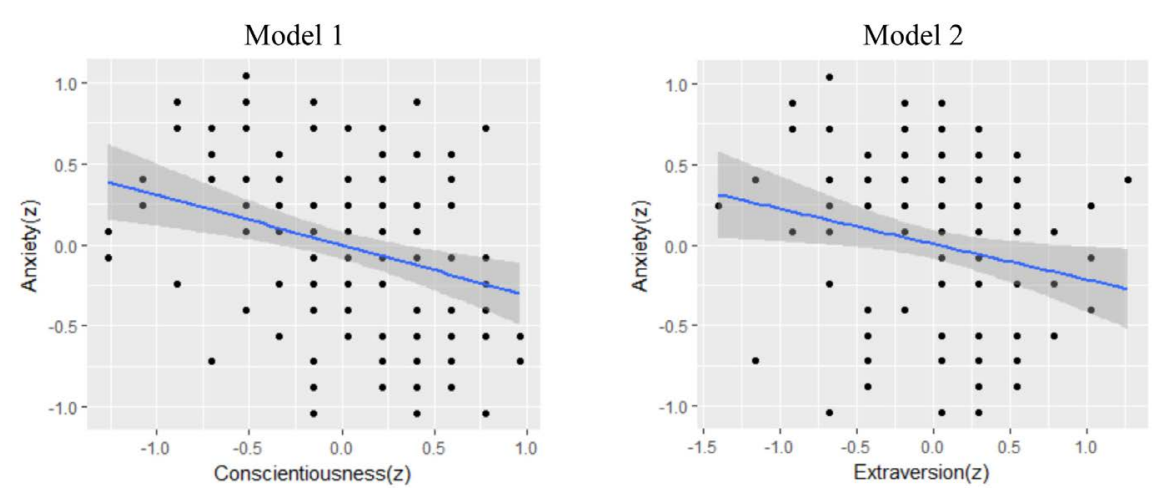

Figure 2. The relationship between anxiety and conscientiousness/extraversion.

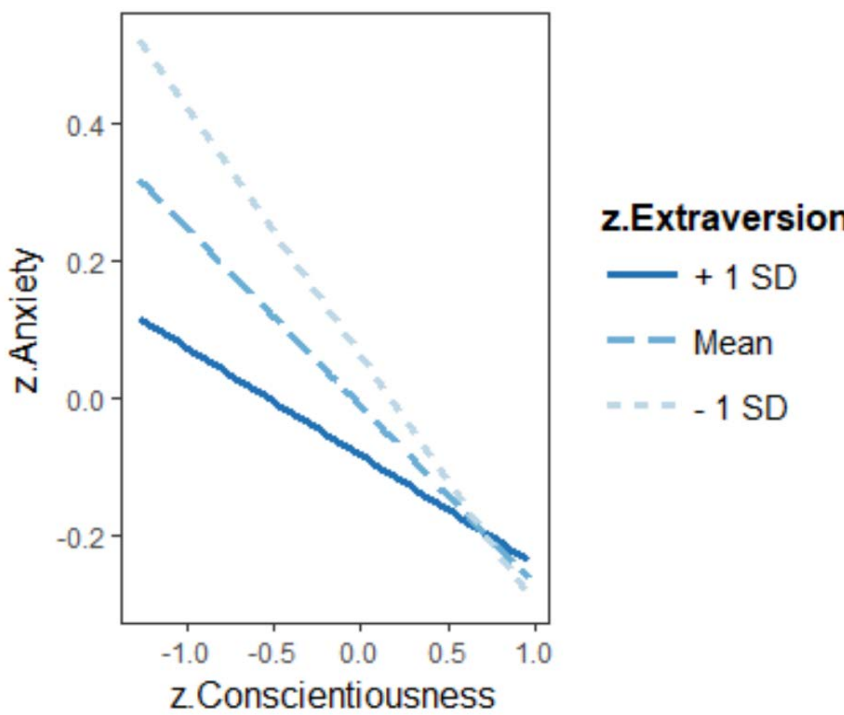

Figure 3. Interaction effect between conscientiousness and extraversion. 


\section{Discussion}

As expected, the first hypothesis was supported. Conscientiousness had a negative main effect on anxiety, which is significant. Hypothesis 2 was supported. The multivariate model showed that the effect was weakened when considering the third-factor extraversion. Conscientiousness and extraversion do not work independently on anxiety. Though there was a mediation effect, the negative effect of conscientiousness on anxiety was still significant. There was an interaction effect between conscientiousness and extraversion. For participants who were high on extraversion, conscientiousness's effect on anxiety was less negative. However, the interaction effect was not significant $(p>.05)$. The results showed that analysis on personality traits was possibly helpful in treating anxiety.

There were several limitations in the current study. First, participants varied much in their demographic background. In the study, participants were aged from 13 to 55 years old, which is a quite large range. Participants were from the different cultural background-China and the US. In that case, participants could have large differences in external factors related to anxiety. If future research has more targeted sample, the proportion of variation in anxiety explained by conscientiousness would be larger. The second limitation was that the Chinese version of the survey was translated by one person was not accurate enough, which could make participants who filled the Chinese version have a different or incorrect understanding of those questions.

\section{Acknowledgements}

I acknowledge academic guidance provided by Dr. Daniel Catterson and Ms. Kaley Curtis. A special thank goes to all participants who help in data collection.

\section{Conflicts of Interest}

The author declares no conflicts of interest regarding the publication of this paper.

\section{References}

Carver, C. S., \& White, T. L. (1994). Behavioral Inhibition, Behavioral Activation, and Affective Responses to Impending Reward and Punishment: The BIS/BAS Scales. Journal of Personality and Social Psychology, 67, 319-333. https://doi.org/10.1037/0022-3514.67.2.319

Craske, M. G., Rauch, S. L., Ursano, R., Prenoveau, J., Pine, D. S., \& Zinbarg, R. E.. (2009). What is an Anxiety Disorder? Depression and Anxiety, 26, 1066-1085. https://doi.org/10.1002/da.20633

Goldberg, L. R. (1992). The Development of Markers for the Big-Five Factor Structure. Psychological Assessment, 4, 26-42. https://doi.org/10.1037/1040-3590.4.1.26

Harris, L. A., \& Dollinger, S. M. C. (2003). Individual Differences in Personality Traits and Anxiety about Aging. Personality and Individual Differences, 34, 187-194. https://doi.org/10.1016/S0191-8869(02)00019-3 
Kotov, R., Gamez, W., Schmidt, F., \& Watson, D. (2010). Linking “Big” Personality Traits to Anxiety, Depressive, and Substance Use Disorders: A Meta-Analysis. Psychological Bulletin, 136, 768-821. https://doi.org/10.1037/a0020327

Middeldorp, C. M., Cath, D. C., Berg, M. V. D., Beem, A. L., Dyck, R. V., \& Boomsma, D. I. (2006). The Association of Personality with Anxious and Depressive Psychopathology. In T. Canli (Ed.), Biology of Personality and Individual Differences; Biology of Personality and Individual Differences (pp. 251-272, Chapter xv, 462 p). New York: Guilford Press.

Naragon-Gainey, K., \& Simms, L. J. (2017). Three-Way Interaction of Neuroticism, Extraversion, and Conscientiousness in the Internalizing Disorders: Evidence of Disorder Specificity in a Psychiatric Sample. Journal of Research in Personality, 70, 16-26. https://doi.org/10.1016/j.jrp.2017.05.003

Vernon, N. A., Evans, M. M., \& Frissen, I. (2016). The Relationship between Dimensions of Personality and Library Anxiety in Graduate Students. Education for Information, 32, 397-410. https://doi.org/10.3233/EFI-160083

Vreeke, L. J., \& Muris, P. (2012). Relations between Behavioral Inhibition, Big Five Personality Factors, and Anxiety Disorder Symptoms in Non-Clinical and Clinically Anxious Children. Child Psychiatry and Human Development, 43, 884-894.

https://doi.org/10.1007/s10578-012-0302-5 